\title{
Induction of apoptosis in MDA-MB-231 human breast carcinoma cells with an ethanol extract of Cyperus rotundus $\mathrm{L}$. by activating caspases
}

\author{
SANG EUN PARK ${ }^{1}$, WON TAK SHIN ${ }^{1}$, CHEOL PARK $^{2}$, SU HYUN HONG ${ }^{3}$, GI-YOUNG KIM ${ }^{4}$, \\ SUNG OK KIM ${ }^{5}$, CHUNG HO RYU ${ }^{6}$, SANG HOON HONG ${ }^{1}$ and YUNG HYUN $\mathrm{CHOI}^{3,7}$ \\ ${ }^{1}$ Department of Internal Medicine, Dongeui University College of Korean Medicine, Busan 614-052; \\ ${ }^{2}$ Department of Molecular Biology, College of Natural Sciences, Dongeui University, Busan 614-714; \\ ${ }^{3}$ Department of Biochemistry, Dongeui University College of Korean Medicine, Busan 614-052; \\ ${ }^{4}$ Laboratory of Immunobiology, Department of Marine Life Sciences, Jeju National University, Jeju 690-756; \\ ${ }^{5}$ Team for Scientification of Korean Medical Intervention (BK21 Plus) and Department of Herbal Pharmacology, \\ Daegu Haany University College of Korean Medicine, Daegu 706-828; ${ }^{6}$ Division of Applied Life Science \\ (BK 21 Program), Institute of Agriculture and Life Science, Gyeongsang National University, Jinju 660-701; \\ ${ }^{7}$ Anti-Aging Research Center and Blue-Bio Industry RIC, Dongeui University, Busan 614-714, Republic of Korea
}

Received May 25, 2014; Accepted August 29, 2014

DOI: $10.3892 /$ or.2014.3507

\begin{abstract}
Cyperus rotundus L. belongs to the Cyperaceae family and is a well documented traditional medicinal herb. Its rhizome has been reported to possess wide spectrum pharmacological activities including anti-inflammatory and antioxidant activity. However, the cellular and molecular mechanisms of the anticancer activity have not been elucidated. In the present study, we investigated the pro-apoptotic effects of $C$. rotundu rhizomes in a human breast carcinoma MDA-MB-231 cell model. Treatment of MDA-MB-231 cells with an ethanol extract of $C$. rotundu rhizomes (EECR) and a methanol extract of $C$. rotund $u$ rhizomes (MECR), but not a water extract of $C$. rotundu rhizomes, resulted in potent antiproliferative activity. The activity of the EECR was higher than that of the MECR and was associated with the induction of apoptosis. The induction of apoptosis by the EECR was associated with upregulation of death receptor 4 (DR4), DR5 and pro-apoptotic Bax, as well as downregulation of anti-apoptotic survivin and Bcl-2. EECR treatment also downregulated Bid expression and activated caspase- 8 and -9 , the respective initiator caspases of the extrinsic and intrinsic apoptotic pathways. The increase in mitochondrial membrane depolarization was correlated with activation of effector caspase-3 and cleavage of poly(ADP-ribose) polymerase, a
\end{abstract}

Correspondence to: Dr Yung Hyun Choi, Department of Biochemistry, Dongeui University College of Korean Medicine, Busan 614-052, Republic of Korea

E-mail: choiyh@deu.ac.kr

Key words: Cyperus rotundus L., MDA-MB-231 cells, apoptosis, caspases vital substrate of activated caspase-3. Blockage of caspase activation by pretreatment with a pan-caspase inhibitor consistently inhibited apoptosis and abrogated growth inhibition in EECR-treated MDA-MB-231 cells. Although reactive oxygen species (ROS) increased following treatment with the EECR, inhibiting ROS with a ROS scavenger did not attenuate EECR-induced apoptosis. Furthermore, inhibitors of phosphatidylinositol 3-kinase (PI3K)/Akt and mitogen-activated protein kinase (MAPK) signaling pathways failed to reverse EECR-induced apoptosis and growth inhibition. These results suggest that the pro-apoptotic activity of the EECR may be regulated by a caspase-dependent cascade through activation of both intrinsic and extrinsic signaling pathways that is not associated with ROS generation or the PI3K/Akt and MAPK pathways.

\section{Introduction}

Breast cancer is the most common type of non-skin human malignancy and the second leading cause of cancer-related mortality among women in Western countries, accounting for $23 \%$ of total cancer cases and $14 \%$ of cancer-related deaths. The incidence of breast cancer is the highest in North America and Europe and the lowest in Asia. However, the incidence of and mortality from breast cancer in poorly developed countries are expected to increase considering the trend in westernization of living $(1,2)$. Although several etiological factors are associated with the occurrence of breast cancer, type of diet, hormone-associated reproductive factors, obesity and atypical hyperplasia of the mammary gland are the most prevalent. Approximately $50 \%$ of breast cancers arise in the absence of known common risk factors, and surgery remains the primary treatment with chemotherapy and radiotherapy used as adjuvants $(3,4)$. Despite the extensive use of multimodal 
therapies, breast cancer remains the leading cause of cancerrelated mortality among women in the world, emphasizing the need for novel therapeutic approaches. To overcome these challenges, novel therapeutic strategies are required for more effective treatment of this serious disease.

Apoptosis, or programmed cell death, is an essential tool for the body to eliminate excess, damaged or harmful cells. In general, cells undergo apoptosis through the extrinsic (death receptor-mediated) and intrinsic (mitochondrial-mediated) pathways $(5,6)$. The extrinsic pathway is triggered by binding of the cell surface death receptors with their relevant ligands, which leads to activation of caspase- 8 and/or -10 . During the intrinsic apoptotic pathway, internal and external stressors lead to the release of apoptogenic proteins from the mitochondria, which along with Apaf-1, activate caspase-9. Caspase- $8,-9$ and -10 are the initiator caspases, as they initiate activation of the effector caspase-3 and -7, triggering the apoptotic caspase cascade $(6,7)$. Caspase- 8 alone is sufficient in some cases to activate caspase- 3 in response to receptor-mediated apoptotic stimuli, however caspase- 8 requires the assistance of the intrinsic apoptotic pathway for enhancing apoptotic stimuli. This can be achieved through caspase-8-mediated proteolytic activation of the pro-apoptotic $\mathrm{Bcl}-2$ homology domain (BH)3-only protein $\mathrm{BH} 3$-interacting domain death agonist (Bid), which then causes mitochondrial outer membrane permeabilization and leads to mitochondrial release of apoptogenic proteins including cytochrome $c(8,9)$. During the past decade, accumulating evidence has suggested that many cancer therapeutic agents induce apoptosis. Although the anticancer agent mechanisms of the apoptotic pathway are controversial, the killing of cancer cells through the induction of apoptosis has been recognized as a novel strategy for identifying chemotherapeutic as well as chemopreventive agents (10-12).

Cyperus rotundus Linn, a sedge in the Cyperaceae family, is a well documented medicinal herb, with a worldwide distribution in tropical and temperate regions. The tuber part of C. rotundus is a commonly used traditional Oriental medicine for treatment of dysmenorrhea and other menstrual irregularities. This herb is also widely used as an analgesic, nerve tonic, nootropic, sedative, anti-spasmodic, anti-malarial, antidiarrheal and a reliever of stomach disorders (13-17). Previous pharmacological investigations indicated that the extracts and/ or components of $C$. rotundus rhizomes have marked hypotensive, anti-mutagenic, anti-obese, neuroprotective, antioxidant, anti-inflammatory and anti-pyretic effects (18-26). In addition, this herb is often prescribed in combination with other herbs to treat stomach ache, inflammation and peptic ulcer disease $(27,28)$. However, despite its valuable effects, little is known about the biochemical basis of the anticancer potential of $C$. rotundus. In the present study, as part of our search for novel biologically active substances to prevent and treat cancer from traditional medicinal resources, we evaluated whether the extracts of $C$.rotundus rhizomes could inhibit cell growth and trigger apoptosis in human breast carcinoma cells.

\section{Materials and methods}

Reagents and antibodies. Fetal bovine serum(FBS),Dulbecco's modified Eagle's medium (DMEM), penicillin, streptomycin and trypsin-ethylenediaminetetraacetic acid (EDTA) were purchased from Gibco-BRL (Gaithersburg, MD, USA). 3-(4,5-Dimethyl-2-thiazolyl)-2,5-diphenyl-2H-tetrazolium bromide (MTT), trypan blue, 4,6-diamidino-2-phenyllindile (DAPI), propidium iodide (PI), paraformaldehyde, 5,5',6,6 -tetrachloro-1,1',3,3'-tetraethyl-imidacarbocyanine iodide (JC-1) and N-acetyl L-cysteine (NAC) were purchased from Sigma-Aldrich (St. Louis, MO, USA). The pan-caspase inhibitor z-VAD-fmk and inhibitors of phosphatidylinositol 3-kinase (PI3K)/Akt and mitogen-activated protein kinase (MAPK) were obtained from Calbiochem (San Diego, CA, USA). DNA ladder size markers were purchased from Invitrogen (Carlsbad, CA, USA). 2',7'-Dichlorofluorescein diacetate (DCFDA) and fluorescein-isothiocyanate (FITC)Annexin V were purchased from Molecular Probes (Eugene, OR, USA) and BD Pharmingen (San Diego, CA, USA), respectively. Caspase activity assay kits and an enhanced chemiluminescence (ECL) kit were purchased from R\&D Systems (Minneapolis, MN, USA) and Amersham (Arlington Heights, IL, USA), respectively. Antibodies were purchased from Santa Cruz Biotechnology (Santa Cruz, CA, USA), Chemicon (Temecula, CA, USA) and Sigma-Aldrich. Peroxidase-labeled donkey anti-rabbit and sheep anti-mouse immunoglobulin were purchased from Amersham. All other chemicals were purchased from Sigma-Aldrich.

Preparation of $C$. rotundus rhizome extracts. $C$. rotundus rhizomes were obtained from the Dongeui Oriental Hospital, Dongeui University College of Oriental Medicine, Busan, Republic of Korea. They were cut into small pieces, ground to powder, passed through a 20-mesh sieve, and transferred to a flask in a 1:10 proportion (drug: solvent, w/v), using methanol, ethanol and water. The materials were protected from light with aluminum foil, and the flasks were shaken at $50 \mathrm{rpm}$ for $24 \mathrm{~h}$ at $60^{\circ} \mathrm{C}$. The extracts were filtered through Whatman paper no. 1 and dried in a Rotavapor at $40^{\circ} \mathrm{C}$, resulting in methanol (MECR), ethanol (EECR) and water (WECR) extracts. The extracts were weighed, resuspended into dimethyl sulfoxide to a final concentration of $100 \mathrm{mg} / \mathrm{ml}$ (extract stock solution) and then diluted with medium to the desired concentration prior to use.

Cell culture. The MDA-MB-231 human breast carcinoma cell line was purchased from the American Type Culture Collection (Manassas, VA, USA) and maintained in DMEM supplemented with $10 \%$ FBS, $1 \%$ L-glutamine and penicillin/streptomycin. The cells were cultured in an incubator with $5 \% \mathrm{CO}_{2}$ at $37^{\circ} \mathrm{C}$.

Cell growth and cell viability assay. Cell growth was assessed using the trypan blue dye exclusion assay. In brief, cells ( $2 \times 10^{4}$ cells/well) were seeded in 6 -well plates. After treatment with the indicated concentrations of the $C$. rotundus extracts for $24 \mathrm{~h}$, the cells were trypsinized and viable cells were counted by trypan blue dye exclusion using a hemocytometer under an inverted microscope (Carl Zeiss, Jena, Germany). Cell viability was determined using the MTT assay. In brief, cells ( $2 \times 10^{4}$ cells/well) were seeded in 24-well plates and exposed to the extracts of $C$. rotundus for $24 \mathrm{~h}$. After treatment, $5 \mathrm{mg} / \mathrm{ml}$ MTT solution was added, followed by a 3-h incubation at 
$37^{\circ} \mathrm{C}$ in the dark. Absorbance of the formazan product was measured at a wavelength of $540 \mathrm{~nm}$ with an enzyme-linked immunosorbent assay (ELISA) reader (Molecular Devices, Sunnyvale, CA, USA). Cells were photographed directly for a morphological study using an inverted microscope.

DAPI nuclear staining. The cells were washed with phosphatebuffered saline (PBS) and fixed with $3.7 \%$ paraformaldehyde in PBS for $10 \mathrm{~min}$ at room temperature. The fixed cells were permeabilized with $0.1 \%$ Triton $\mathrm{X}-100$ for $10 \mathrm{~min}$, the supernatant was removed and the cells were washed three times with PBS. The cells were incubated with $2.5 \mu \mathrm{g} / \mathrm{ml}$ DAPI for $10 \mathrm{~min}$ at room temperature in the dark. The cells were then washed twice with PBS and DAPI-stained cell nuclei (apoptotic nuclei stained intensely) and were observed with a fluorescence microscope (Carl Zeiss).

Agarose gel electrophoresis. Cells were lysed in a buffer containing $10 \mathrm{mM}$ Tris- $\mathrm{HCl}, \mathrm{pH} 7.4,150 \mathrm{mM} \mathrm{NaCl}, 5 \mathrm{mM}$ EDTA and $0.5 \%$ Triton X-100 for $1 \mathrm{~h}$ at room temperature for the DNA fragmentation assay. Lysates were vortexed and cleared by centrifugation at $19,000 \mathrm{x}$ g for $30 \mathrm{~min}$ at $4^{\circ} \mathrm{C}$. A $25: 24: 1$ (v/v/v) equal volume of neutral phenol:chloroform:isoamyl alcohol was used to extract DNA from the supernatant, followed by electrophoretic analysis on $1.5 \%$ agarose gels containing $0.1 \mu \mathrm{g} / \mathrm{ml}$ ethidium bromide.

Flow cytometric detection of apoptosis. A combination of Annexin V-FITC and PI staining distinguishes between early (Annexin $\mathrm{V}^{+} / \mathrm{PI}$ ) and late (Annexin $\mathrm{V}^{+} / \mathrm{PI}^{+}$) apoptotic, necrotic and live cells. After the cells were treated with the EECR for $24 \mathrm{~h}$, they were trypsinized, washed with PBS, and resuspended in $100 \mu \mathrm{l}$ binding buffer containing $5 \mu \mathrm{l}$ Annexin V-FITC and $5 \mu \mathrm{PI}$ for $15 \mathrm{~min}$ at room temperature in the dark. The cells were immediately analyzed by flow cytometry (FACSCalibur; Becton-Dickinson, San Jose, CA, USA). The percentages of apoptotic cells (Annexin $\mathrm{V}^{+}$cells) are presented as the means \pm standard deviation as previously described (29).

Protein extraction and western blot analysis. The cells were collected by trypsin-EDTA and lysed with lysis buffer $(20 \mathrm{mM}$ sucrose, $1 \mathrm{mM}$ EDTA, $20 \mu \mathrm{M}$ Tris-Cl, pH 7.2, $1 \mathrm{mM}$ DTT, $10 \mathrm{mM} \mathrm{KCl}, 1.5 \mathrm{mM} \mathrm{MgCl}_{2}, 5 \mu \mathrm{g} / \mathrm{ml}$ pepstatin A, $10 \mu \mathrm{g} / \mathrm{ml}$ leupeptin and $2 \mu \mathrm{g} / \mathrm{ml}$ aprotinin) containing protease inhibitors for $30 \mathrm{~min}$ at $4^{\circ} \mathrm{C}$. The mixtures were centrifuged $(10,000 \mathrm{x} \mathrm{g})$ for $10 \mathrm{~min}$ at $4^{\circ} \mathrm{C}$, and the supernatants were collected as whole-cell extracts. Protein content was determined using the Bio-Rad protein assay reagent (Hercules, CA, USA) and bovine serum albumin as the standard according to the manufacturer's instructions to determine protein concentrations. After normalization, an equal amount of protein was subjected to electrophoresis on sodium dodecyl sulfate-polyacrylamide gels and transferred to nitrocellulose membranes (Schleicher \& Schuell, Keene, NH, USA) by electroblotting. The blots were blocked with $5 \%$ skim milk for $1 \mathrm{~h}$ at room temperature. The blots were incubated overnight with primary antibodies, followed by horseradish peroxidase-conjugated donkey antirabbit and sheep anti-mouse immunoglobulin for $1 \mathrm{~h}$. The immunoreactive bands were revealed by enhanced chemiluminescence with a commercially available ECL kit.
Measurement of mitochondrial membrane potential (MMP). MMP values were determined using the dual-emission potential-sensitive probe, JC-1. Briefly, cells were collected and incubated with $10 \mu \mathrm{M} \mathrm{JC}-1$ for $30 \mathrm{~min}$ at $37^{\circ} \mathrm{C}$ in the dark. After JC-1 was removed, the cells were washed with PBS to remove unbound dye, and the amount of $\mathrm{JC}-1$ retained by 10,000 cells/sample was measured at 488 and $575 \mathrm{~nm}$ using a flow cytometer.

Caspase activity assay. Caspase activities were determined with colorimetric assay kits, which utilize synthetic tetrapeptides [Asp-Glu-Val-Asp (DEAD) for caspase-3, Ile-Glu-Thr-Asp (IETD) for caspase-8 and Leu-Glu-His-Asp (LEHD) for caspase-9] labeled with p-nitroaniline (pNA). Briefly, EECR-treated and untreated cells were lysed in the supplied lysis buffer. The supernatants were collected and incubated with the supplied reaction buffer containing dithiothreitol and DEAD-pNA, IETD-pNA or LEHD-pNA as substrates at $37^{\circ} \mathrm{C}$. The reactions were measured by changes in absorbance at $405 \mathrm{~nm}$ using an ELISA reader.

Measurement of reactive oxygen species (ROS). ROS production was monitored using the stable nonpolar dye DCFDA. The cells were seeded at a density of $1 \times 10^{5}$ cells $/ \mathrm{ml}$, allowed to attach for $24 \mathrm{~h}$ and exposed to $200 \mu \mathrm{g}$ EECR for various periods. The cells were incubated with $10 \mathrm{mM}$ DCFDA for $20 \mathrm{~min}$ at $37^{\circ} \mathrm{C}$ in the dark. ROS production in the cells was monitored with a flow cytometer using CellQuest Pro software.

Statistical analysis. Data are reported as means \pm standard deviation of three independent experiments. A one-way analysis of variance was performed to determine differences. $\mathrm{p}<0.05$ was considered to indicate a statistically significant difference.

\section{Results}

Antiproliferative activity of $C$. rotundus rhizome extracts in MDA-MB-231 cells. To investigate the effects of $C$. rotundus rhizome extracts on MDA-MB-231 cell growth, the cells were treated with various concentrations of the MECR, EECR and WECR for $24 \mathrm{~h}$, and cell number and viability were measured by trypan blue exclusion and the MTT assay, respectively. As shown in Fig. 1, the MECR and EECR markedly inhibited cell proliferation and viability of MDA-MB-231 cells in a concentration-dependent manner. For example, cell viability was inhibited by $>30$ or $65 \%$ in cells exposed to 150 or $300 \mu \mathrm{g} / \mathrm{ml}$ of the EECR, respectively, compared to that in untreated controls. In contrast, the WECR was not cytotoxic under the same experimental conditions. The EECR possessed stronger cytotoxicity than MECR; thus, we used the EECR for further studies.

Induction of apoptosis in MDA-MB-231 cells by EECR treatment. Cell morphology was assessed by DAPI staining. The results indicated that the nuclear structure of control cells remained intact, whereas nuclear chromatin condensation and fragmentation, characteristics of apoptosis, were observed in cells treated with the EECR and were associated with numerous cellular morphological changes (Fig. 2A and B). 

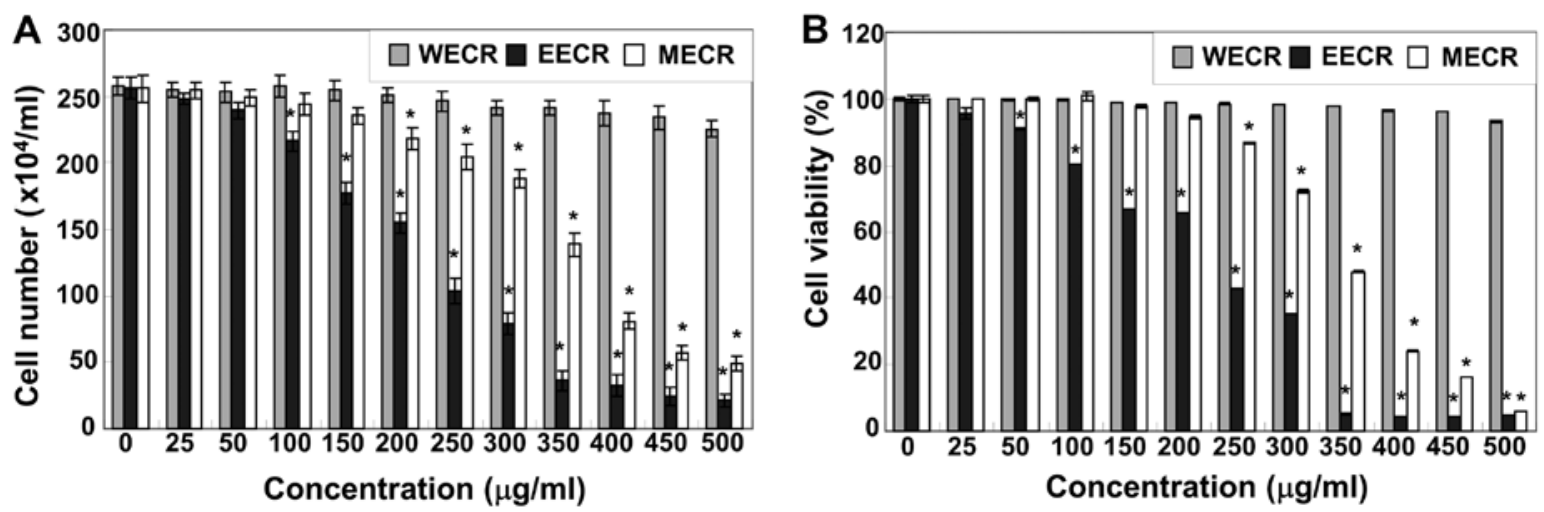

Figure 1. Effect of Cyperus rotundus rhizome extracts on cell growth in MDA-MB-231 cells. The cells were treated with the indicated concentrations of an ethanol extract of $C$. rotundu rhizomes (EECR), a methanol extract of $C$. rotundu rhizomes (MECR), and a water extract of $C$. rotundu rhizomes (WECR) for $24 \mathrm{~h}$. (A) Viable cells were determined using the trypan blue dye exclusion assay. (B) Inhibition of cell viability was measured by the metabolic-dye-based MTT assay. Data are means \pm standard deviation of three independent experiments (" $\mathrm{p}<0.05$ vs. untreated control).
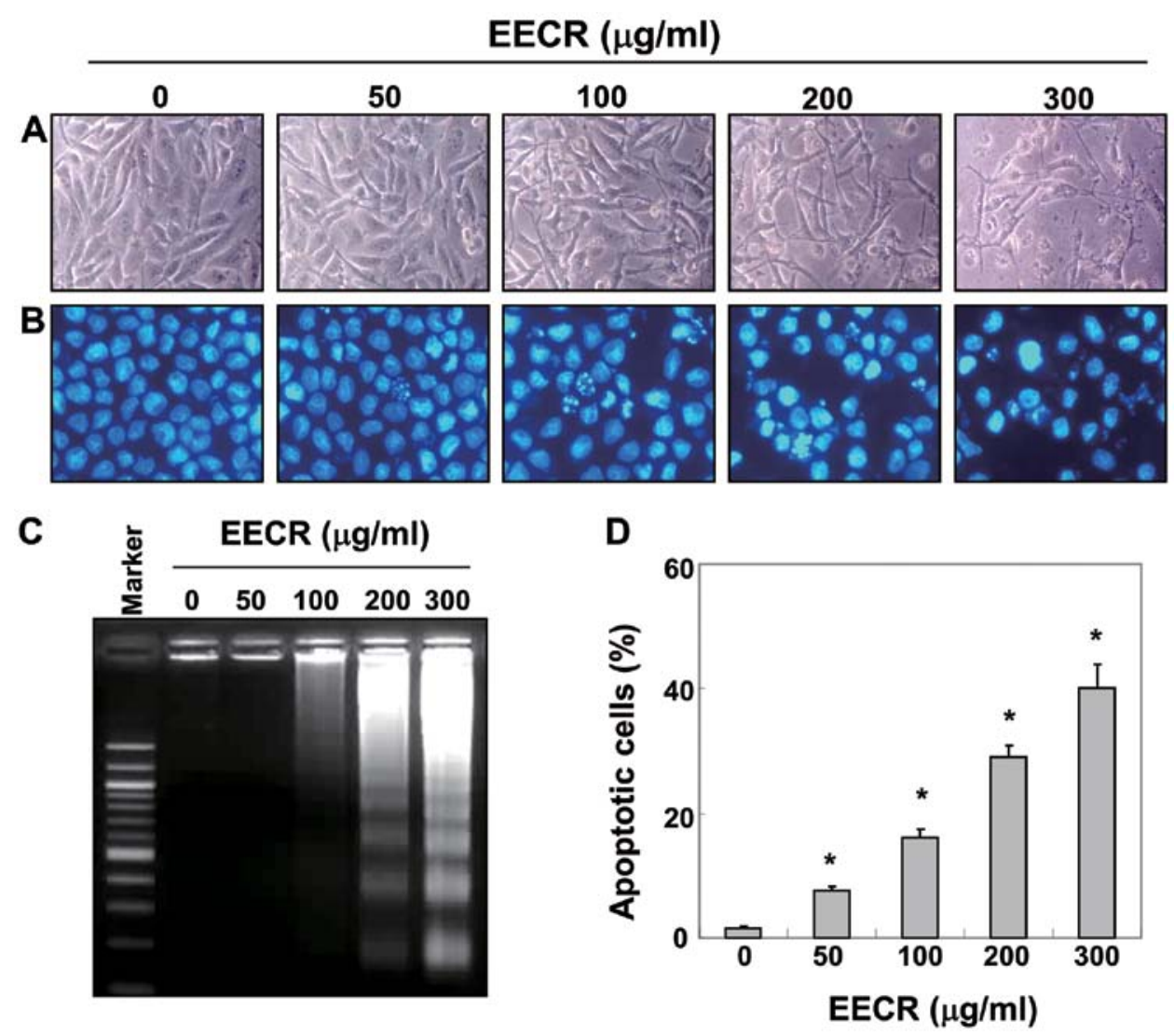

Figure 2. Induction of apoptosis by an ethanol extract of Cyperus rotundu rhizomes (EECR) in MDA-MB-231 cells. The cells were treated with the indicated concentrations of the EECR for $24 \mathrm{~h}$. (A) Cell morphology was visualized by light microscopy. Magnification, x200. (B) Nuclei stained with DAPI solution were photographed with a fluorescence microscope using a blue filter. Magnification, x400. (C) Genomic DNA was extracted, electrophoresed in a 1.5\% agarose gel and visualized by ethidium bromide staining to analyze DNA fragmentation. (D) The cells were stained with Annexin V-FITC and propidium iodide for flow cytometry analysis to quantify the degree of apoptosis induced by the EECR. Data are means \pm standard deviation of three independent experiments ( $\mathrm{p}<0.05$ vs. untreated control).

In particular, cell shrinkage and cytoplasm condensation appeared in a dose-dependent manner after EECR treatment. In addition, treatment with the EECR induced progressive accumulation of fragmented DNA, which appeared as a typical ladder pattern of DNA fragmentation due to internucleosomal cleavage associated with apoptosis, in a concentration-dependent manner (Fig. 2C). Furthermore, we evaluated apoptotic induction by flow cytometry analysis with Annexin V and PI staining. As shown in Fig. 2D, treatment with the EECR resulted in an increased accumulation of apoptotic cells compared with that of untreated control cells.

Effects of EECR treatment on expression of apoptosis-related genes. The death receptor and corresponding pro-apoptotic 


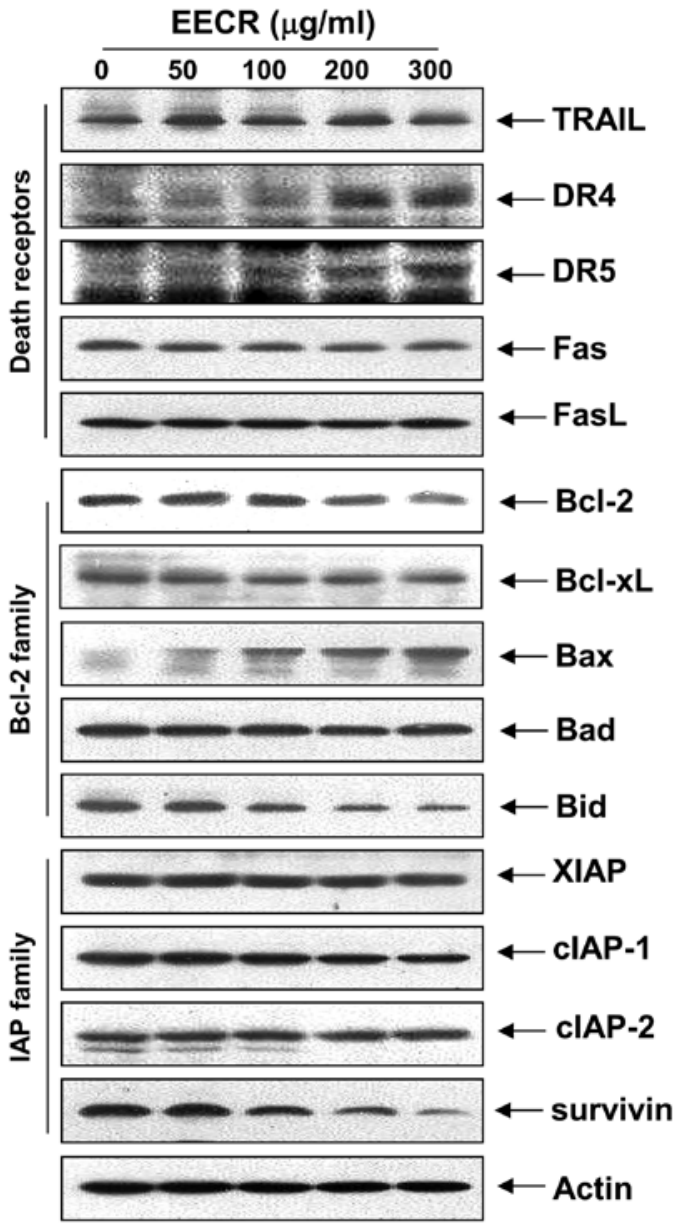

Figure 3. Effects of an ethanol extract of Cyperus rotundu rhizomes (EECR) on the levels of apoptosis-related proteins in MDA-MB-231 cells. The cells were treated with the indicated concentrations of the EECR for $24 \mathrm{~h}$. The cells were lysed and then equal amounts of cell lysates (30-50 $\mu \mathrm{g})$ were separated on SDS-polyacrylamide gels and transferred to nitrocellulose membranes. The membranes were probed with the indicated antibodies and the proteins were visualized using an enhanced chemiluminescent detection system. Actin was used as the internal control.

ligands were examined by western blot analysis to determine which apoptosis pathway contributes to EECR-induced apoptosis. The results showed that the levels of TRAIL, Fas and FasL expression were relatively unchanged in response to EECR treatment; however, the levels of death receptor (DR) 4 and DR5 markedly increased in response to EECR treatment (Fig. 3). Next, we examined the effects of the EECR on the levels of Bcl-2 family proteins. The results of immunoblotting revealed downregulation of anti-apoptotic Bcl-2, but not Bcl-xL, in MDA-MB-231 cells (Fig. 3). However, treatment with the EECR caused a marked increase in pro-apoptotic Bax expression, but not Bad. In addition, relative protein expression of anti-apoptotic survivin decreased in a concentration-dependent manner compared to that in control cells, whereas expression of XIAP, cIAP-1 and cIAP-2 was relatively constant in EECR-treated MDA-MB-231 cells (Fig. 3).

Activation of caspases and degradation of poly(ADP-ribose) polymerase (PARP) by EECR treatment. We next examined the effect of the EECR on caspase activity to determine whether caspase activation occurs during EECR-induced
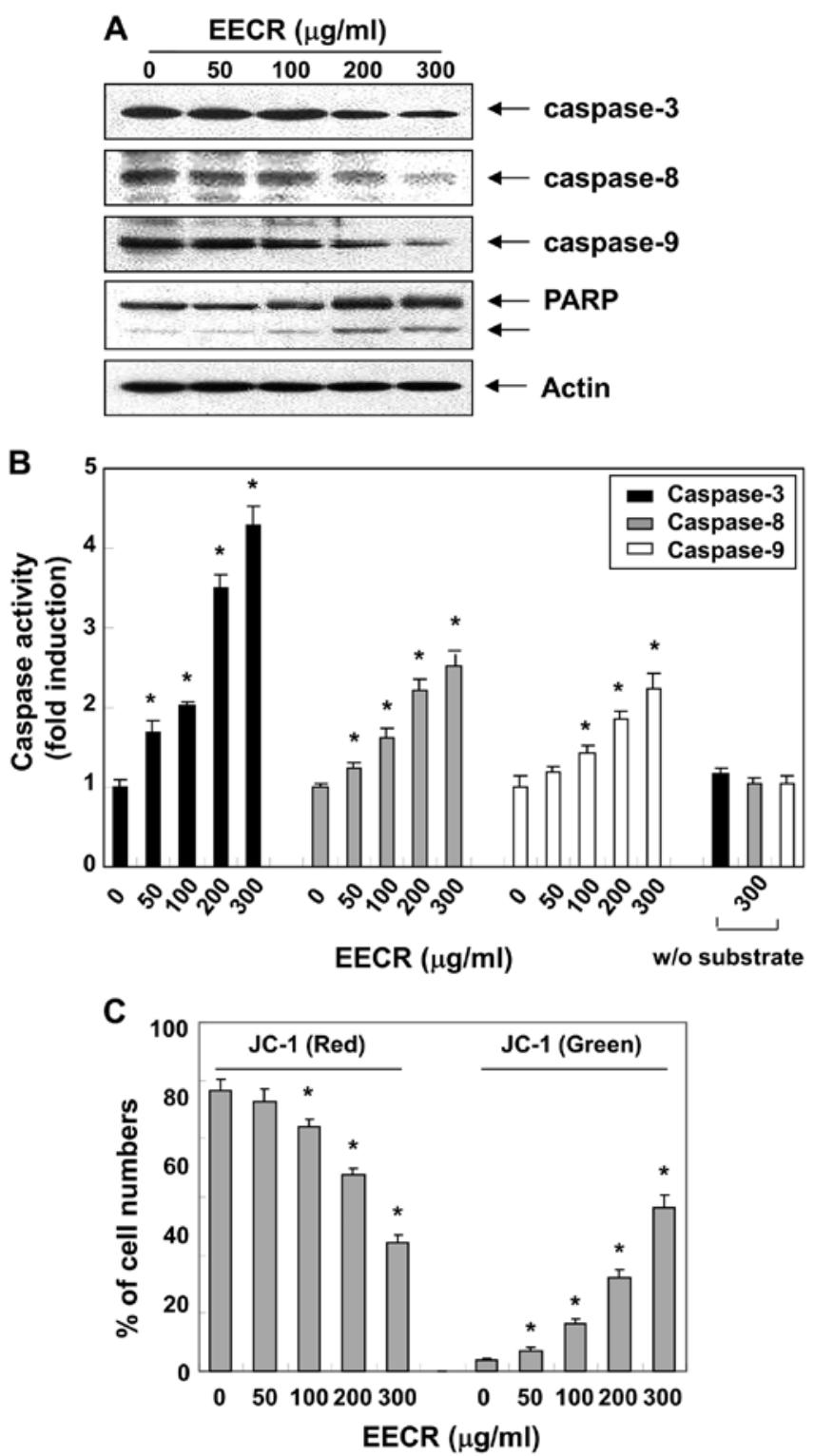

Figure 4. Activation of caspases, degradation of the poly(ADP-ribose) polymerase (PARP) and loss of mitochondrial membrane potential (MMP) following treatment with an ethanol extract of Cyperus rotundu rhizomes (EECR) in MDA-MB-231 cells. The cells were treated with the indicated concentration of the EECR for $24 \mathrm{~h}$. (A) The cells were lysed and equal amounts of cell lysates $(30 \mu \mathrm{g})$ were separated on SDS-polyacrylamide gels and transferred to nitrocellulose membranes. The membranes were probed with the indicated antibodies. Proteins were visualized using an enhanced chemiluminescent detection system. Actin was used as the internal control. (B) Cells grown under the same conditions as (A) were collected and lysed. Aliquots were incubated with DEVD-pNA, IETD-pNA and LEHD-pNA for caspase-3, -8 and -9 individually at $37^{\circ} \mathrm{C}$ for $1 \mathrm{~h}$. The released fluorescence products were measured. (C) The cells were stained with $10 \mu \mathrm{M} \mathrm{JC}-1$ and then incubated at $37^{\circ} \mathrm{C}$ for $20 \mathrm{~min}$, and mean JC-1 fluorescence intensity was detected using a flow cytometer. Cell numbers of red vs. green fluorescence show live cells with intact MMP and dead cells with lost MMP, respectively. Data are means \pm standard deviation of three independent experiments $\left({ }^{*} \mathrm{p}<0.05\right.$ vs. untreated control).

apoptosis. Fig. 4A shows that treatment of MDA-MB-231 cells with the EECR decreased pro-caspase- 8 and -9 levels, which are initiator caspases of the extrinsic and intrinsic apoptotic pathways, respectively. In conjunction with the decrease in pro-caspase- 8 and -9 expression, western blotting revealed 
A
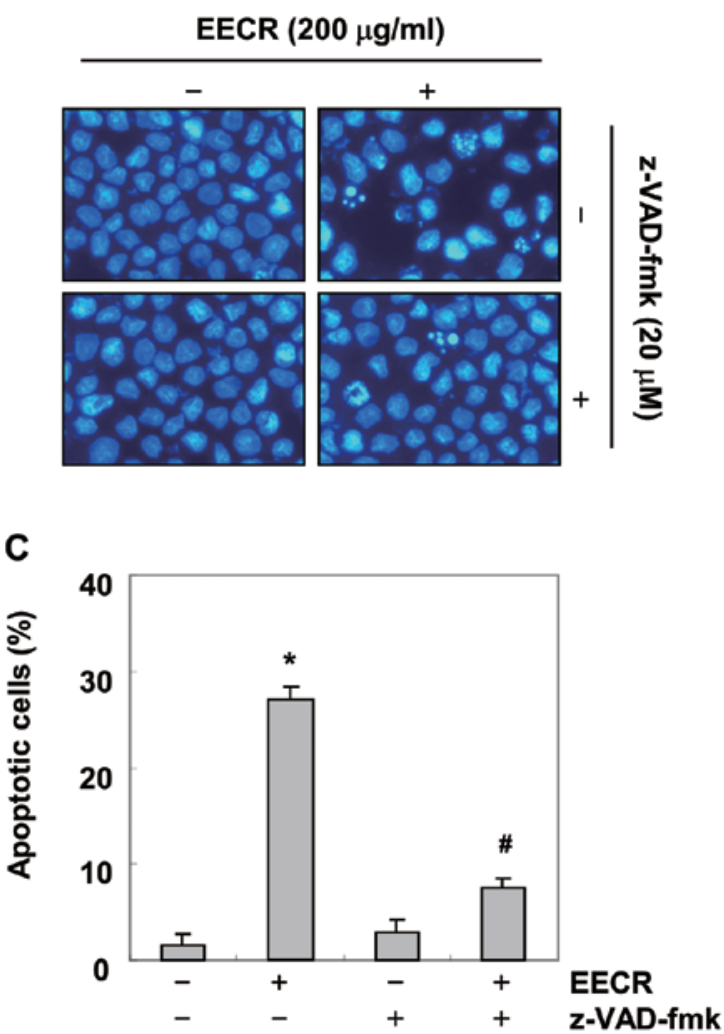

B

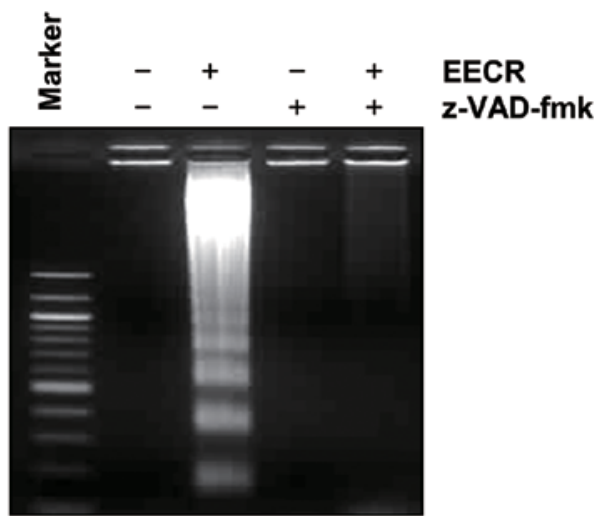

D

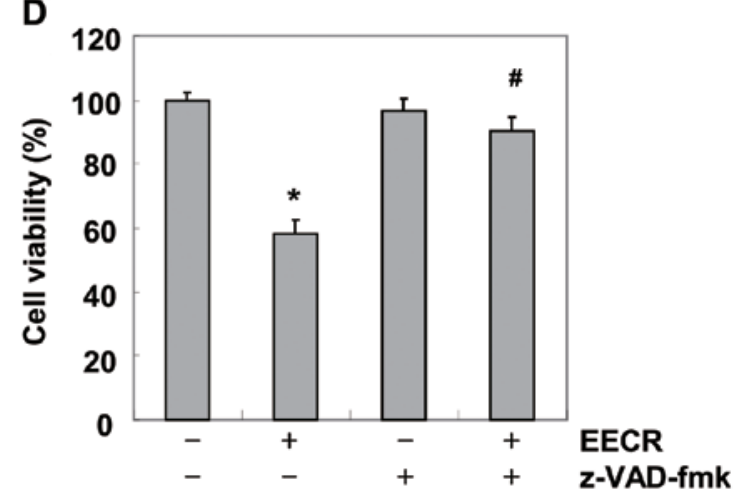

Figure 5. Inhibition of ethanol extract of Cyperus rotundu rhizomes (EECR)-induced apoptosis by the pan-caspases inhibitor in MDA-MB-231 cells. Cells were pretreated for $1 \mathrm{~h}$ with or without $\mathrm{z}$-VAD-fmk $(20 \mu \mathrm{M})$, and then with $200 \mu \mathrm{g} / \mathrm{ml}$ EECR for an additional $24 \mathrm{~h}$. (A) The cells were stained with DAPI for $10 \mathrm{~min}$ and photographed with a fluorescence microscope using a blue filter. Magnification, x400. (B) DNA fragmentation was analyzed by extracting the fragmented DNA and separating it by electrophoresis in a $1.5 \%$ agarose gel containing ethidium bromide. (C) The cells were fixed and stained with Annexin V-FITC and propidium iodide for flow cytometry analysis. (D) Cell viability was measured by the MTT assay. Results are expressed as percentage of the vehicle-treated control $\pm \mathrm{SD}$ of three separate experiments $\left({ }^{*} \mathrm{p}<0.05\right.$ vs. untreated control; ${ }^{\#} \mathrm{p}<0.05$ vs. EECR-treated cells).

that EECR treatment of MDA-MB-231 cells also resulted in the downregulation of pro-caspase-3. Furthermore, activation of caspases by the EECR was confirmed by measuring enzyme activity using the specific synthetic substrates for each caspase. As indicated in Fig. 4B, we observed a dose-dependent gradual increase in caspase-3, -8 and -9 activities in EECR-treated MDA-MB-231 cells similar to the proteolytic processing of pro-caspases. Activation of caspase-3 was further evidenced from cleavage of PARP from a $116 \mathrm{kDa}$ band to a $89 \mathrm{kDa}$ fragment, a substrate of active caspase-3, which also serves as a marker of cells undergoing apoptosis (30).

Effects of the EECR on apoptosis induction for mitochondrial signaling. Since the EECR activated caspase-9, we investigated whether it would affect EECR-induced apoptosis associated with mitochondrial signaling. Thus, we examined the effects of the EECR on mitochondrial membrane integrity, one of the early events leading to apoptosis, using the JC-1 fluorescent probe. The results in Fig. 4C indicate that treatment with the EECR clearly elicited dissipation of the MMP when compared to that in control cells. The extrinsic apoptotic signaling cascade starts with activation of caspase- 8 and truncation of $\mathrm{Bid}$ (tBid), a $\mathrm{BH} 3$ pro-apoptotic protein, which translocates to the mitochondrial membrane, allowing activation of pro-apoptotic proteins $(8,9)$. Therefore, we further examined the effect of the EECR on the level of Bid. As indicated in Fig. 3, EECR treatment caused a decrease in the amount of the Bid pro-form, which is indirect evidence of protein truncation and activation, suggesting that EECR-induced apoptosis in MDA-MB-231 cells may occur via activation of caspase- 8 and Bid truncation.

Inhibition of EECR-induced apoptosis by a caspase inhibitor. To further confirm the significance of caspase activation in EECR-induced apoptosis, we examined the effects of the general caspase inhibitor, z-VAD-fmk. As shown in Fig. 5A and B, pre-treatment with z-VAD-fmk completely abrogated the appearance of cells with apoptotic features, such as chromatin condensation and formation of apoptotic bodies, and attenuated the accumulation of fragmented DNA. A flow cytometric analysis and MTT assay indicated that pretreatment of cells with z-VAD-fmk prevented EECR-induced accumulation of apoptotic cell population and growth inhibition (Fig. 5C and D). These results show that EECR-induced apoptosis in MDA-MB-231 cells occurred via a caspase-dependent pathway.

EECR-induced apoptosis is independent of ROS generation in $M D A-M B-231$ cells. Oxidative stress occurs due to an imbalance in pro-oxidant and antioxidant levels in cells. Excess ROS generation through an imbalance between pro-oxidants and antioxidants leads to damage of cellular macromolecules 
A

Time (min)

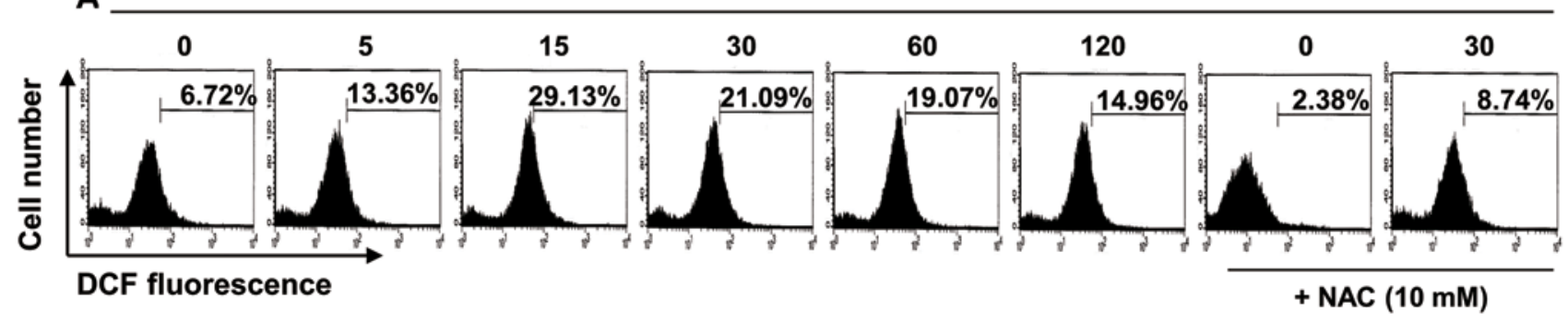

B
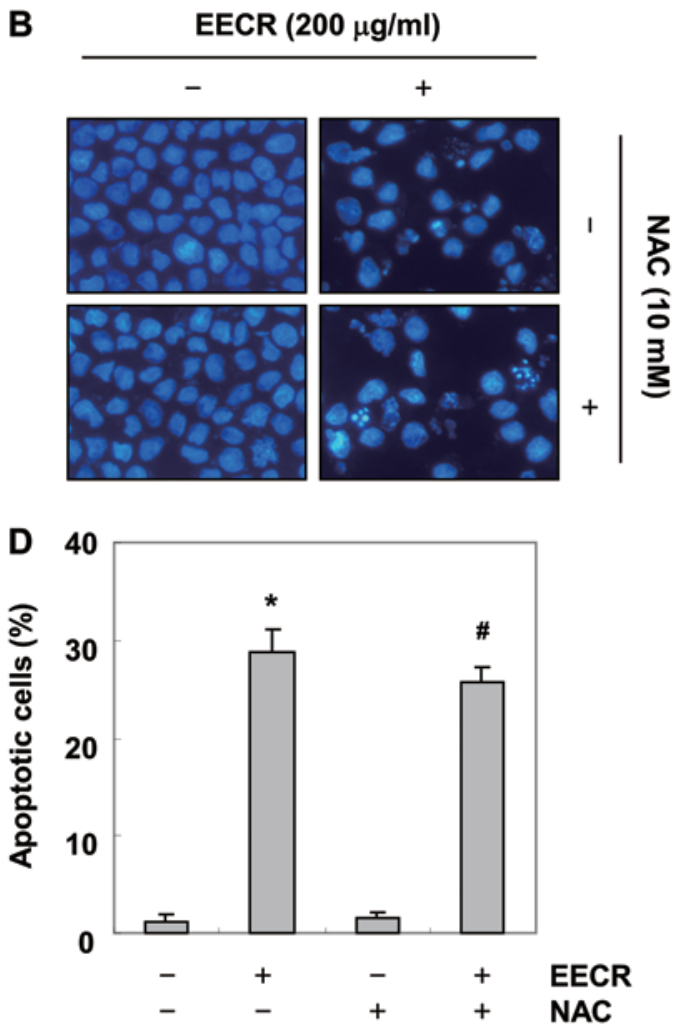

C
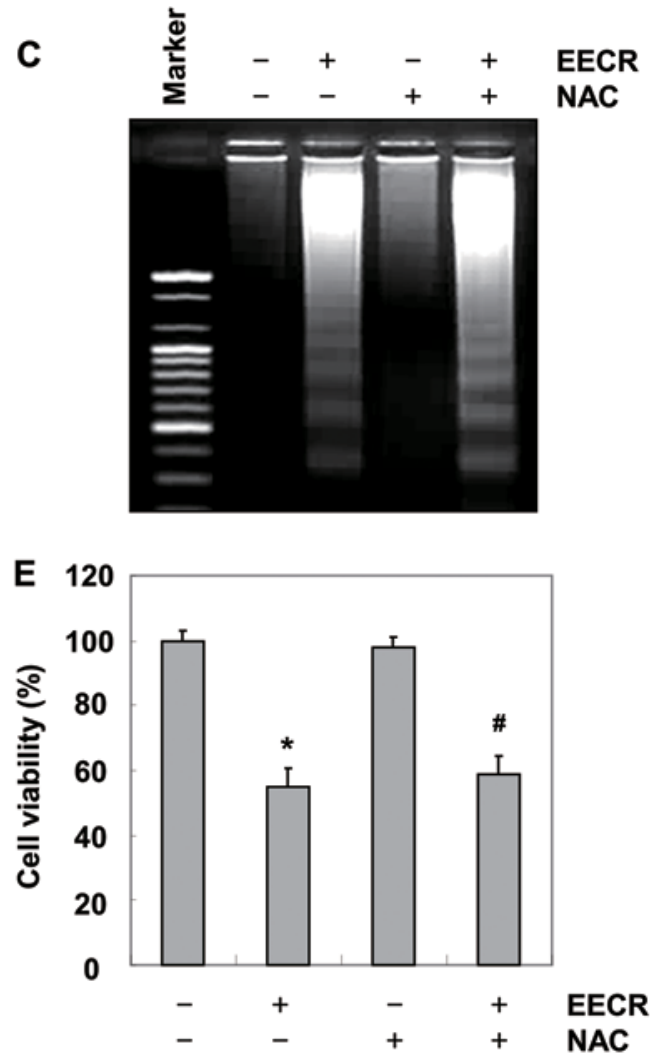

Figure 6. Effect of ethanol extract of Cyperus rotundu rhizome (EECR) on the formation of reactive oxygen species (ROS) in MDA-MB-231 cells. (A) Cells were treated with $200 \mu \mathrm{g} / \mathrm{ml}$ EECR for the indicated times or pretreated with $10 \mathrm{mM} \mathrm{NAC}$ for $1 \mathrm{~h}$ prior to $200 \mu \mathrm{g} / \mathrm{ml}$ EECR for $15 \mathrm{~min}$ and then collected. The cells were stained with $10 \mu \mathrm{M}$ DCFDA for DNA flow cytometry analysis. At each time point, fluorescent intensity was measured using a DNA flow cytometer. Each point represents the mean of two independent experiments. (B-E) Cells were pretreated for $1 \mathrm{~h}$ with or without NAC (10 mM) and then with $200 \mu \mathrm{g} / \mathrm{ml}$ EECR for an additional $24 \mathrm{~h}$. (B) The cells were stained with DAPI for 10 min and photographed with a fluorescence microscope using a blue filter. Magnification, $x 400$. (C) DNA fragmentation was analyzed by extracting the fragmented DNA and separating it by electrophoresis in a $1.5 \%$ agarose gel containing ethidium bromide. (D) The cells were fixed and stained with Annexin V-FITC and propidium iodide for flow cytometry analysis. (E) Cell viability was measured by the MTT assay. Results are expressed as percentage of the vehicle-treated control \pm SD of three separate experiments $\left({ }^{*}\right.$ p $<0.05$ vs. untreated control; ${ }^{\#}$ p<0.05 vs. EECR-treated cells). NAC, N-acetyl L-cysteine; DCFDA, 2',7'-dichlorofluorescein diacetate.

including DNA, proteins and lipids, and eventually results in physical and chemical damage to tissues that may lead to cell death $(31,32)$. Therefore, we investigated whether ROS generation was also involved in EECR-induced apoptosis. As shown in Fig. 6A, the EECR markedly increased intracellular ROS levels within 15 min, and pretreatment with NAC, a well known ROS scavenger, markedly attenuated EECR-induced ROS generation. However, pretreatment with NAC did not block EECR-induced apoptotic morphological changes or DNA fragmentation (Fig. 6B and C). Moreover, NAC did not inhibit EECR-induced apoptosis and growth inhibition (Fig. 6D and E). Collectively, these results clearly indicate that the EECR-induced apoptosis in MDA-MB-231 cells is not mediated by ROS generation.
Activation of Akt and MAPKs is not involved in EECR-induced apoptosis in $M D A-M B-231$ cells. Next, we investigated the effect of EECR treatment on the expression and activities of PI3K/Akt and MAPKs to determine whether these signaling pathways play a role in mediating the observed apoptotic response. Western blot analysis showed that total Akt protein and phosphorylated Akt levels did not change significantly in response to EECR treatment. In addition, the EECR did not lead to phosphorylation of the three MAPKs including extracellular signal-regulated kinase (ERK), p38 MAPK and c-Jun NH2-terminal kinase (JNK) (Fig. 7), and there was also no effect on steady-state levels of total MAPK proteins in MDA-MB-231 cells treated with EECR. Moreover, pretreatment with a representative PI3K/Akt inhibitor, LY294002 and 


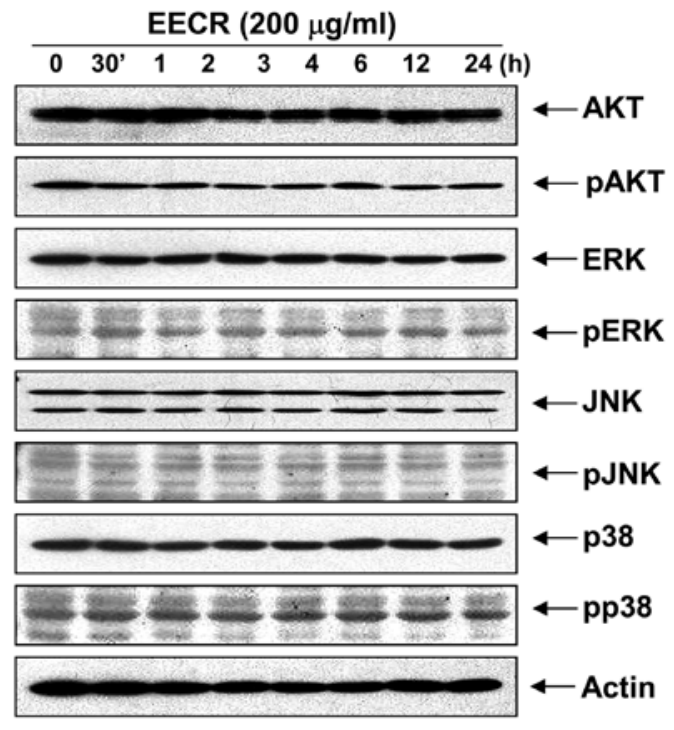

Figure 7. Effects of an ethanol extract of Cyperus rotundu rhizomes (EECR) treatment on the levels of total and phosphorylated Akt and mitogen activated protein kinase (MAPK) proteins in MDA-MB-231 cells. The cells were treated with $200 \mu \mathrm{g} / \mathrm{ml}$ EECR for the indicated times. The cells were lysed and then equal amounts of cell lysates (30-50 $\mu \mathrm{g})$ were separated on SDS-polyacrylamide gels and transferred to nitrocellulose membranes. The membranes were probed with the indicated antibodies and the proteins were visualized using an enhanced chemiluminescent detection system. Actin was used as an internal control.

inhibitors of MAPKs (PD98059, a potent inhibitor of ERK; SP600125, a potent inhibitor of JNK; SB203589, a specific inhibitor of the p38 MAPK) did not have a significant effect on EECR treatment (Fig. 8). Collectively, these results suggest that the PI3K/Akt and MAPK pathways did not play a role in regulating EECR-induced apoptosis of MDA-MB-231 cells.

\section{Discussion}

Although the extracts and components isolated from C. rotundus possess a wide range of biological activities that may contribute to health beneficial effects, the mechanisms of the antiproliferative actions on malignant cell growth have not yet been elucidated. In our search for new natural sources of apoptosis-inducing agents from traditional medicinal plants, we studied the efficiency of extracts from $C$. rotundus. In the present study, using the MDA-MB-231 human breast cancer cell line, we demonstrated inhibited cell growth and viability by the EECR and the MECR as well as changes in cell morphology in a concentration-dependent manner (Figs. 1 and 2A). To further confirm that the EECR-induced antiproliferative effects were related to apoptotic cell death, induction of apoptosis by the EECR was confirmed by measuring nuclear chromatin condensation, DNA fragmentation and accumulation of apoptotic cells (Fig. 2B-D).

Dysregulated apoptosis induces a number of pathological conditions, including cancer, and failure of apoptosis leads to an imbalance in cell number, which in turn leads to tumorigenesis. Therefore, induction of apoptosis in malignant cells has emerged as an important strategy for cancer therapy $(5,6)$. Our data demonstrated that EECR-induced apoptosis was associated with induction of DR4 and DR5, inhibition of survivin, and cleavage of Bid (Fig. 3). The data also indicated that treatment with the EECR induced activation of caspases-3, -8, and -9 and concomitant proteolytic degradation of PARP and loss of MMP (Fig. 4). Among the two major apoptotic pathways, the extrinsic pathway requires recruitment of the death receptor-associated death domain and caspase-8/-10, which results in caspase-8/-10 activation and subsequent activation of downstream executioner caspases including caspase- 3 and -7 and apoptosis $(33,34)$. The intrinsic pathway is triggered by cell stressors and many chemotherapeutic agents, resulting in the induction of mitochondrial dysfunction. Mitochondrial dysfunction induces activation of caspase- 9 and subsequently activates effector caspases. Following activation of caspase-3, several specific substrates including PARP are cleaved, eventually leading to apoptosis (30). In some cells, caspase- 8 also mediates the intrinsic pathway via cleavage of the pro-apoptotic Bid protein $(8,9)$. In particular, caspases are regulated by various molecules, including members of the $\mathrm{Bcl}-2$ and IAP families. Bcl-2 family proteins are involved in the control of the apoptotic process by interactions between pro-apoptotic (such as Bax and Bad) and anti-apoptotic (such as Bcl-2 and Bcl-xL) members, particularly those of the intrinsic pathway with mitochondrial dysfunction. Cellular proteins in the IAP family (including XIAP, cIAP-1, cIAP-2 and survivin) specifically inhibit caspase- 3 and -9 activities, yet they do not inhibit caspase-8 $(6,7)$. In the intrinsic pathway, members of the IAP family bind directly to a principal caspase, such as pro-caspase- 3 and -9 , and inhibit apoptosis induced by Bcl-2 family proteins. Therefore, the downregulation of IAP family proteins relieves the triggering block of pro-apoptotic signaling and the execution caspases, thus activating cell death $(35,36)$. In addition to activation of caspases, EECR treatment resulted in a significant increase in Bax expression and a decrease in Bcl-2 expression (Fig. 3), suggesting that changes in the ratio of pro-apoptotic and anti-apoptotic Bcl-2 family proteins may contribute to the apoptosis-promoting activity of the EECR. Our results also revealed that pretreatment with the pan-caspase inhibitor, z-VAD-fmk, significantly attenuated EECR-induced apoptosis (Fig. 5). These data indicate that caspases are the key molecules mediating EECR-induced apoptosis, supporting the hypothesis that the caspase-dependent pathway may be involved in EECR-induced apoptosis of MDA-MB-231 cells.

Accumulating evidence indicates that the redox state of cells is involved in cell fate and suggests the possibility that ROS-mediated oxidative DNA damage and depolarization of mitochondrial membranes play an important role in apoptosis $(32,37)$. In the present study, intracellular ROS levels increased markedly within 15 min by EECR treatment in MDA-MB-231 cells; however, the quenching of ROS generation with the antioxidant NAC, a widely used ROS scavenger, did not confer significant protection against EECR-elicited apoptosis, demonstrating that the generation of ROS is not required for apoptosis induced by EECR treatment of MDA-MB-231 cells. In addition to ROS generation, it has been demonstrated that the phosphorylation states of some regulatory proteins are also crucial events along the pathways controlling cell survival and death. Among them, the PI3K/Akt pathway plays an important role controlling the balance between cell survival and apoptosis. This pathway is normally activated in 


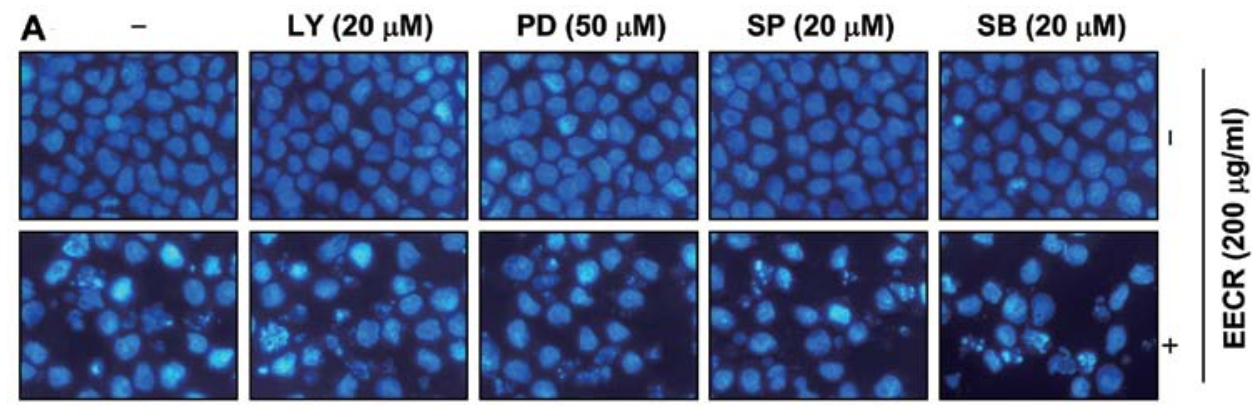

B

\begin{tabular}{|c|c|c|c|c|c|c|c|c|c|c|c|}
\hline & - & + & - & - & - & - & + & - & - & - & LY \\
\hline & - & - & + & - & - & - & - & + & - & - & PD \\
\hline & - & - & - & + & - & - & - & - & + & - & SP \\
\hline & - & - & - & - & + & - & - & - & - & + & SB \\
\hline & - & - & - & - & - & + & + & + & + & + & EECR \\
\hline
\end{tabular}

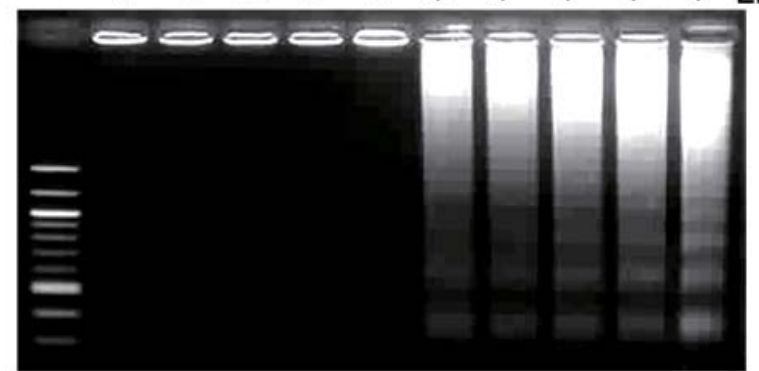

C

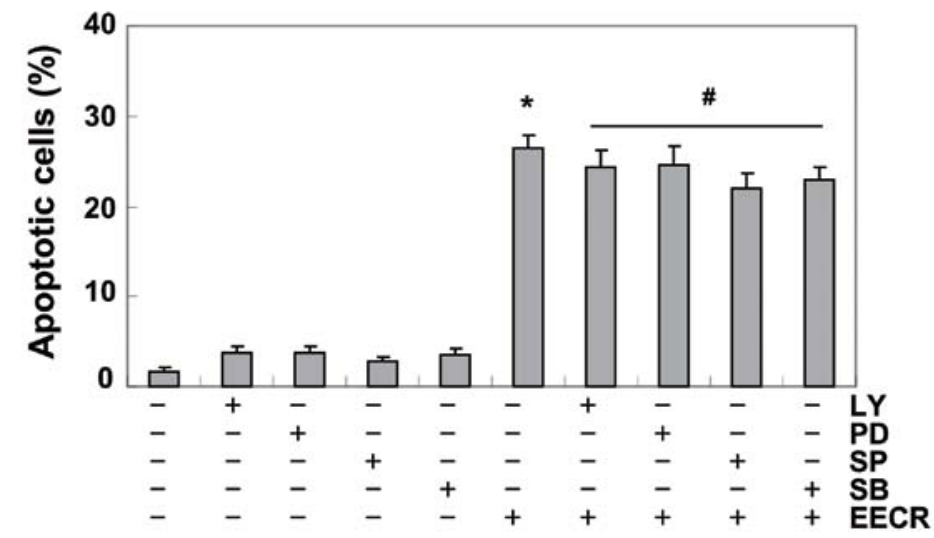

Figure 8. Effects of PI3K/Akt and mitogen activated protein kinase (MAPK) signaling pathway inhibitors on ethanol extract of $C y p e r u s$ rotundu rhizomes (EECR)-induced apoptosis in MDA-MB-231 cells. Cells were pretreated for $1 \mathrm{~h}$ with or without the indicated inhibitors (LY, LY294002; PD, D98059; SP, SP600125; and SB, SB203589), and then with $200 \mu \mathrm{g} / \mathrm{ml}$ EECR for an additional $24 \mathrm{~h}$. (A) The cells were stained with DAPI for $10 \mathrm{~min}$ and photographed with a fluorescence microscope using a blue filter. Magnification, x400. (B) DNA fragmentation was analyzed by extracting the fragmented DNA and separating it by electrophoresis in a $1.5 \%$ agarose gel containing ethidium bromide. (C) The cells were fixed and stained with Annexin V-FITC and propidium iodide for flow cytometry analysis. Results are expressed as percentage of the vehicle-treated control \pm SD of three separate experiments $\left({ }^{*} \mathrm{p}<0.05\right.$ vs. untreated control; n.s., not significant vs. EECR-treated cells; ${ }^{\# p}$ < 0.05 vs. EECR-treated cells).

a wide variety of cancers and results in enhanced resistance to apoptosis through multiple mechanisms. Therefore, inhibiting PI3K/Akt decreases cell survival and enhances the effects of chemotherapeutic drugs in many types of cancer cells $(38,39)$. Another well-established apoptotic signaling cascade is regulated by MAPKs, including JNK, ERK and p38 MAPK. In general, they are activated in response to various stimuli and participate in a variety of signaling pathways that regulate diverse cellular processes including cell growth, differentiation and stress responses $(40,41)$. However, PI3K/Akt as well as MAPKs were not activated by EECR treatment, and specific inhibitors of these pathways did not reduce or increase apoptosis. These results demonstrate that activation of PI3K/Akt as well as MAPKs is not a necessary step in EECR-induced apoptosis in MDA-MB-231 cells.
In summary, the results of the present study demonstrate that the death receptor-mediated pathway is initiated by ligation of the transmembrane death receptor to activate membraneproximal caspases (caspase-8), which in turn activate effector caspases such as caspase-3. Second, the mitochondrialmediated pathway requires disruption of the mitochondrial membrane, which induces activation of caspase- 9 and thereby initiates the apoptotic caspase cascade. In addition, crosstalk between the two pathways may be mediated by truncation of Bid, which may act as a potential feedback loop to amplify EECR-induced caspase-dependent apoptosis. Although further studies are required to identify the active compounds, these novel phenomena have not been previously described and provide important new insight into the anticancer effects of the EECR. 


\section{Acknowledgements}

This study was supported by the Basic Science Research Program through the National Research Foundation of Korea (NRF) grant funded by the Korea government (no. 2012046358).

\section{References}

1. Jemal A, Bray F, Center MM, Ferlay J, Ward E and Forman D: Global cancer statistics. CA Cancer J Clin 61: 69-90, 2011.

2. Forouzanfar MH, Foreman KJ, Delossantos AM, Lozano R Lopez AD, Murray CJ and Naghavi M: Breast and cervical cancer in 187 countries between 1980 and 2010: a systematic analysis. Lancet 378: 1461-1484, 2011

3. Senkus E, Kyriakides S, Penault-Llorca F, Poortmans P, Thompson A, Zackrisson S, Cardoso F; ESMO Guidelines Working Group: Primary breast cancer: ESMO Clinical Practice Guidelines for diagnosis, treatment and follow-up. Ann Oncol 24 (Suppl 6): vi7-vi23, 2013.

4. Spector D, Deroo LA and Sandler DP: Lifestyle behaviors in black and white women with a family history of breast cancer Prev Med 52: 394-397, 2011

5. Danial NN and Korsmeyer SJ: Cell death: critical control points. Cell 116: 205-219, 2004.

6. Jin Z and El-Deiry WS: Overview of cell death signaling pathways. Cancer Biol Ther 4: 139-163, 2005.

7. Caroppi P, Sinibaldi F, Fiorucci L and Santucci R: Apoptosis and human diseases: mitochondrion damage and lethal role of released cytochrome $\mathrm{c}$ as proapoptotic protein. Curr Med Chem 16: 4058-4065, 2009.

8. Kaufmann T, Strasser A and Jost PJ: Fas death receptor signalling: roles of Bid and XIAP. Cell Death Differ 19: 42-50, 2012.

9. Zha J, Weiler S, Oh KJ, Wei MC and Korsmeyer SJ: Posttranslational N-myristoylation of BID as a molecular switch for targeting mitochondria and apoptosis. Science 290: 1761-1765, 2000.

10. Chung KM and Yu SW: Interplay between autophagy and programmed cell death in mammalian neural stem cells. BMB Rep 46: 383-390, 2013.

11. Mansilla S, Llovera L and Portugal J: Chemotherapeutic targeting of cell death pathways. Anticancer Agents Med Chem 12: 226-238, 2012

12. Rufini A and Melino G: Cell death pathology: the war against cancer. Biochem Biophys Res Commun 414: 445-450, 2011.

13. Thebtaranonth C, Thebtaranonth Y, Wanauppathamkul S and Yuthavong Y: Antimalarial sesquiterpenes from tubers of Cyperus rotundus: structure of 10,12-peroxycalamenene, a sesquiterpene endoperoxide. Phytochemistry 40: 125-128, 1995.

14. Zhu M, Luk HH, Fung HS and Luk CT: Cytoprotective effects of Cyperus rotundus against ethanol induced gastric ulceration in rats. Phytother Res 11: 392-394, 1997.

15. Uddin SJ, Mondal K, Shilpi JA and Rahman MT: Antidiarrhoeal activity of Cyperus rotundus. Fitoterapia 77: 134-136, 2006.

16. Sharma R and Gupta R: Cyperus rotundus extract inhibits acetylcholinesterase activity from animal and plants as well as inhibits germination and seedling growth in wheat and tomato. Life Sci 80: 2389-2392, 2007.

17. Kilani-Jaziri S, Neffati A, Limem I, Boubaker J, Skandrani I, Sghair MB, Bouhlel I, Bhouri W, Mariotte AM, Ghedira K, Dijoux Franca MG and Chekir-Ghedira L: Relationship correlation of antioxidant and antiproliferative capacity of Cyperus rotundus products towards K562 erythroleukemia cells. Chem Biol Interact 181: 85-94, 2009.

18. Yazdanparast $\mathrm{R}$ and Ardestani A: In vitro antioxidant and free radical scavenging activity of Cyperus rotundus. J Med Food 10 667-674, 2007.

19. Ardestani A and Yazdanparast R: Cyperus rotundus suppresses AGE formation and protein oxidation in a model of fructosemediated protein glycoxidation. Int J Biol Macromol 41: 572-578, 2007.

20. Gupta MB, Palit TK, Singh N and Bhargava KP: Pharmacological studies to isolate the active constituents from Cyperus rotundus possessing anti-inflammatory, anti-pyretic and analgesic activities. Indian J Med Res 59: 76-82, 1971.
21. Seo WG, Pae HO, Oh GS, Chai KY, Kwon TO, Yun YG, Kim NY and Chung HT: Inhibitory effects of methanol extract of Cyperus rotundus rhizomes on nitric oxide and superoxide productions by murine macrophage cell line, RAW 264.7 cells. J Ethnopharmacol 76: 59-64, 2001.

22. Kilani S, Ben Ammar R, Bouhlel I, Abdelwahed A, Hayder N, Mahmoud A, Ghedira K and Chekir-Ghedira L: Investigation of extracts from (Tunisian) Cyperus rotundus as antimutagens and radical scavengers. Environ Toxicol Pharmacol 20: 478-484, 2005.

23. Tsoyi K, Jang HJ, Lee YS, Kim YM, Kim HJ, Seo HG, Lee JH, Kwak JH, Lee DU and Chang KC: (+)-Nootkatone and (+)-valencene from rhizomes of Cyperus rotundus increase survival rates in septic mice due to heme oxygenase-1 induction. J Ethnopharmacol 137: 1311-1317, 2011.

24. Lemaure B, Touché A, Zbinden I, Moulin J, Courtois D, Macé K and Darimont C: Administration of Cyperus rotundus tubers extract prevents weight gain in obese Zucker rats. Phytother Res 21: 724-730, 2007.

25. Kumar KH and Khanum F: Hydroalcoholic extract of Cyperus rotundus ameliorates $\mathrm{H}_{2} \mathrm{O}_{2}$-induced human neuronal cell damage via its anti-oxidative and anti-apoptotic machinery. Cell Mol Neurobiol 33: 5-17, 2013

26. Hemanth Kumar K, Tamatam A, Pal A and Khanum F: Neuroprotective effects of Cyperus rotundus on SIN-1 induced nitric oxide generation and protein nitration: ameliorative effect against apoptosis mediated neuronal cell damage. Neurotoxicology 34 : 150-159, 2013.

27. Fu XC, Shan HL, Bai HB and Hu R: Protective effect of Jiangbaiweiyan tablet on ethanol-induced gastric mucosa injury in rats. Zhejiang Da Xue Xue Bao Yi Xue Ban 40: 391-394, 2011 (In Chinese).

28. He CL, Yi PF, Fan QJ, Shen HQ, Jiang XL, Qin QQ, Song Z, Zhang C, Wu SC, Wei XB, Li YL and Fu BD: Xiang-Qi-Tang and its active components exhibit anti-inflammatory and anticoagulant properties by inhibiting MAPK and NF- $\kappa \mathrm{B}$ signaling pathways in LPS-treated rat cardiac microvascular endothelial cells. Immunopharmacol Immunotoxicol 35: 215-224, 2013.

29. Lee SJ, Hwang SO, Noh EJ, Kim DU, Nam M, Kim JH, Nam JH and Hoe KL: Transactivation of bad by vorinostat-induced acetylated p53 enhances doxorubicin-induced cytotoxicity in cervical cancer cells. Exp Mol Med 46: e76, 2014.

30. Lazebnik YA, Kaufmann SH, Desnoyers S, Poirier GG and Earnshaw WC: Cleavage of poly(ADP-ribose) polymerase by a proteinase with properties like ICE. Nature 371: 346-347, 1994.

31. Matés JM, Segura JA, Alonso FJ and Márquez J: Intracellular redox status and oxidative stress: implications for cell proliferation, apoptosis, and carcinogenesis. Arch Toxicol 82: 273-299, 2008.

32. Trueba GP, Sánchez GM and Giuliani A: Oxygen free radical and antioxidant defense mechanism in cancer. Front Biosci 9: 2029-2044, 2004.

33. Ashkenazi A and Dixit VM: Apoptosis control by death and decoy receptors. Curr Opin Cell Biol 11: 255-260, 1999.

34. Peter ME and Krammer PH: The CD95(APO-1/Fas) DISC and beyond. Cell Death Differ 10: 26-35, 2003.

35. Deveraux QL and Reed JC: IAP family proteins - suppressors of apoptosis. Genes Dev 13: 239-252, 1999.

36. Roy N, Deveraux QL, Takahashi R, Salvesen GS and Reed JC: The c-IAP-1 and c-IAP-2 proteins are direct inhibitors of specific caspases. EMBO J 16: 6914-6925, 1997.

37. Schumacker PT: Reactive oxygen species in cancer cells: live by the sword, die by the sword. Cancer Cell 10: 175-176, 2006.

38. Yoeli-Lerner M and Toker A: Akt/PKB signaling in cancer: a function in cell motility and invasion. Cell Cycle 5: 603-605, 2006.

39. Hu L, Hofmann J, Lu Y, Mills GB and Jaffe RB: Inhibition of phosphatidylinositol 3'-kinase increases efficacy of paclitaxel in in vitro and in vivo ovarian cancer models. Cancer Res 62: 1087-1092, 2002.

40. Kim EK and Choi EJ: Pathological roles of MAPK signaling pathways in human diseases. Biochim Biophys Acta 1802: 396-405, 2010

41. Wagner EF and Nebreda AR: Signal integration by JNK and p38 MAPK pathways in cancer development. Nat Rev Cancer 9: 537-549, 2009. 